\title{
Withdrawal of antiepileptic drug treatment in childhood epilepsy: factors related to age
}

\author{
Miyako Murakami, Tohru Konishi, Yoshihiro Naganuma, Kazuhisa Hongou, \\ Miwa Yamatani
}

Department of

Pediatrics, Faculty of Medicine, Toyama

Medical and

Pharmaceutical

University, Toyama

City, Japan

M Murakami

T Konishi

Y Naganuma

K Hongou

M Yamatani

Correspondence to:

Department of Pediatrics,

Toyama Medical and

Pharmaceutical University,

2630 Sugitani, Toyama City

930-01, Japan.

Received 22 June 1994

and in final revised form

29 June 1995

Accepted 5 July 1995
Dr Miyako Murakami,

\begin{abstract}
The clinical and electroencephalographic changes with age were evaluated in 304 patients with childhood epilepsies, whose antiepileptic treatment had been discontinued after a seizure free period of more than three years. The withdrawal rate differed significantly between epileptic syndromes, being higher in idiopathic epilepsy and lower in symptomatic epilepsy. The age at withdrawal was characteristic for each epileptic syndrome, and generally showed two peaks: at preadolescence and early school age. Forty one $(13.5 \%)$ of the 304 patients experienced relapses. The relapse rate differed between epileptic syndromes. Relapses occurred at a unique age in each epileptic syndrome, and were frequent in preadolescence and early adulthood. Electroencephalography that still showed paroxysmal discharges at withdrawal did not necessarily predict the occurrence of a relapse, but the changes in background activity with age, which may indicate maturation of the CNS, were significantly different between the patients with and those without relapses. The results suggest that age related to each epileptic syndrome should be considered when deciding on withdrawal of antiepileptic drugs.
\end{abstract}

Table 1 Rates of antiepileptic drug withdrawal and relapse

\begin{tabular}{|c|c|c|c|c|}
\hline \multirow[b]{2}{*}{ Syndrome } & \multicolumn{2}{|c|}{ Cases with withdrawal } & \multirow{2}{*}{\multicolumn{2}{|c|}{ Relapse cases (\%) }} \\
\hline & Total cases & 5 year follow up & & \\
\hline $\begin{array}{l}\text { Idiopathic PE: } \\
\text { BECT } \\
\text { CEOP }\end{array}$ & $\begin{array}{l}62 / 88 \\
10 / 11\end{array}$ & $\begin{array}{c}53 / 55(96 \cdot 4) \\
7 / 7(100)\end{array}$ & $\begin{array}{l}6(9 \cdot 7) \\
0-\end{array}$ & $8 \cdot 3 \%$ \\
\hline $\begin{array}{l}\text { Symptomatic PE: } \\
\text { Frontal } \\
\text { Temporal } \\
\text { Parietal } \\
\text { Occipital } \\
\text { Undifferentiated }\end{array}$ & $\begin{array}{r}24 / 95 \\
22 / 81 \\
4 / 15 \\
10 / 31 \\
0 / 33\end{array}$ & $\begin{array}{l}23 / 42(54 \cdot 8) \\
20 / 32(62 \cdot 5) \\
4 / 11(36 \cdot 4) \\
10 / 19(52 \cdot 6) \\
0 / 4-\end{array}$ & $\begin{array}{l}5(20 \cdot 8) \\
4(18 \cdot 2) \\
1(25 \cdot 0) \\
2(20 \cdot 0) \\
-\end{array}$ & $20 \cdot 0 \%$ \\
\hline Cryptogenic PE & $58 / 122$ & $51 / 55(92 \cdot 7)$ & 5 & $8 \cdot 6 \%$ \\
\hline $\begin{array}{l}\text { Idiopathic GE: } \\
\text { Childhood absence } \\
\text { Juvenile absence } \\
\text { JME } \\
\text { GM (awakening) } \\
\text { Other GM }\end{array}$ & $\begin{array}{c}16 / 22 \\
4 / 6 \\
2 / 6 \\
11 / 29 \\
34 / 65\end{array}$ & $\begin{array}{c}11 / 12(91 \cdot 7) \\
4 / 4(100) \\
2 / 4(50 \cdot 0) \\
9 / 13(69 \cdot 2) \\
34 / 39(87 / 2)\end{array}$ & $\begin{array}{l}1(6 \cdot 3) \\
1(25 \cdot 0) \\
2(100) \\
3(27 \cdot 3) \\
5(14 \cdot 7)\end{array}$ & $17 \cdot 9 \%$ \\
\hline $\begin{array}{l}\text { Symptomatic GE: } \\
\text { West syndrome } \\
\text { Lennox } \\
\text { Others }\end{array}$ & $\begin{array}{l}7 / 20 \\
0 / 6 \\
2 / 13\end{array}$ & $\begin{array}{l}6 / 18(33 \cdot 3) \\
0 / 6 \quad- \\
2 / 13(15 \cdot 4)\end{array}$ & $\frac{3}{0}^{3(42 \cdot 9)}$ & $33 / 3 \%$ \\
\hline Infantile convulsion & $35 / 67$ & $30 / 31(96 / 8)$ & 2 & $5 \cdot 7 \%$ \\
\hline Unclassified & $3 / 24$ & $3 / 22(13 / 6)$ & 1 & $33 \cdot 3 \%$ \\
\hline Total & $304 / 735$ & $269 / 387(69 \cdot 5)$ & 41 & $13.5 \%$ \\
\hline
\end{tabular}

Numbers in parentheses are \%; BECT = benign childhood epilepsy with centrotemporal spikes CEOP $=$ childhood epilepsy with occipital paroxysmus; JME = juvenile myoclonic epilepsy GM (awakening) = grand mal on awakening epilepsy; PE = partial epilepsy; GE = generalised epilepsy.

\section{$(7$ Neurol Neurosurg Psychiatry 1995;59:477-481)}

Keywords: childhood epilepsy; antiepileptic drug; aging; epileptic syndrome

The prognosis is generally good in childhood epilepsies, ${ }^{1-5}$ and in many cases it is possible to discontinue antiepileptic drugs after an adequate seizure free period. But there is still dispute regarding the indications and timing. ${ }^{6-13}$

We discontinued antiepileptic drug treatment in patients with childhood epilepsies on the basis of the seizure free period. ${ }^{12}{ }^{13}$ In this study, the clinical and EEG courses of patients with different epileptic syndromes in whom antiepileptic drug treatment was successfully discontinued were compared, and we evaluated the factors related to age for the management of childhood epilepsies.

\section{Patients and methods}

Three hundred and four patients, in whom antiepileptic drug treatment was discontinued between January 1980 and December 1992 were examined. All the patients were followed up for more than one year after withdrawal. The reasons for withdrawing the antiepileptic drug were as follows: (a) over three years had elapsed since the last seizure (over two years in benign infantile convulsion), and (b) the EEG findings did not become worse on withdrawal of the antiepileptic drug (remaining paroxysmal EEG discharges did not affect the decision). All patients had undergone chronic long term antiepileptic drug treatment, mainly with carbamazepine for partial epilepsies and valproic acid for generalised epilepsies. The tapering off period took more than six months for each antiepileptic drug. The EEGs were obtained at six month intervals during and after antiepileptic drug treatment. In some patients, measurement of EEG background activity on awakening was periodically performed by means of power spectral analysis.

\section{Results}

ANTIEPILEPTIC DRUG WITHDRAWAL AND EPILEPTIC SYNDROMES (table 1)

There were $304(41.4 \%)$ patients with antiepileptic drug withdrawal among the 734 patients, including $269(69.5 \%)$ patients with antiepileptic drug withdrawal among the 387 patients followed up for more than five years. According to the classification of epilepsies and epileptic syndromes (International 
Table 2 Comparison of clinical features of the patients in whom antiepileptic drug treatment could and could not be discontinued

\begin{tabular}{|c|c|c|}
\hline & $\begin{array}{l}\text { Antiepileptic drug withdrawal } \\
(n=269)\end{array}$ & $\begin{array}{l}\text { Antiepileptic drug treatment } \\
(n=118)\end{array}$ \\
\hline $\begin{array}{l}\text { Epileptic syndromes } \\
\text { Onset age }\end{array}$ & $\begin{array}{l}\text { IPE, CPE and IGE } \\
6 \cdot 0(3 \cdot 2) \text { years (mean age) } \\
\text { School age }\end{array}$ & $\begin{array}{l}\text { SPE, SGE, and unclassified } \\
5.6(3.8) \text { years } \\
\text { Under } 3 \text { or over } 12 \text { years }\end{array}$ \\
\hline $\begin{array}{l}\text { Family history } \\
\text { History of febrile } \\
\text { convulsion (FC) }\end{array}$ & FC: $8 \cdot 4 \%$, Epilepsy: $13 \cdot 0 \%$ & FC: $9 \cdot 6 \%$, epilepsy: $7 \cdot 7 \%$ \\
\hline $\begin{array}{l}\text { Convulsion (FC) } \\
\text { Psychomotor delay }\end{array}$ & $\begin{array}{l}29 \cdot 0 \% \\
\text { Mental retardation: } 6 \cdot 1 \% \\
\text { Motor handicaps: } 1 \cdot 5 \%\end{array}$ & $\begin{array}{l}21 \cdot 2 \% \\
50 \cdot 0 \% \\
11 \cdot 5 \%\end{array}$ \\
\hline Clinical seizures & $\begin{array}{l}\text { Controlled with one year } \\
\text { of treatment }\end{array}$ & $\begin{array}{l}\text { Poor response to the initial } \\
\text { treatment } \\
\text { Frequent seizures at the first visit } \\
25 \%\end{array}$ \\
\hline $\begin{array}{l}\text { Antiepileptic drug } \\
\text { treatment }\end{array}$ & $\begin{array}{l}\text { Number of antiepileptic drugs: } \\
1 \cdot 5(0 \cdot 8) \\
\text { Monotherapy: } 61 \cdot 8 \%\end{array}$ & $\begin{array}{l}2 \cdot 7(1 \cdot 1) \\
11 \cdot 5 \%\end{array}$ \\
\hline
\end{tabular}

Numbers in parentheses are SD

Table 3 Mean ages at onset and antiepileptic drug withdrawal, and duration of antiepileptic drug treatment and seizure cessation

\begin{tabular}{|c|c|c|c|c|}
\hline Syndrome & Onset age (y) & $\begin{array}{l}\text { Antiepileptic drug } \\
\text { duration }(y)\end{array}$ & $\begin{array}{l}\text { Withdrawal } \\
\text { age }(y)\end{array}$ & Seizures $(y)$ \\
\hline $\begin{array}{l}\text { Idiopathic PE } \\
\text { BECT } \\
\text { CEOP }\end{array}$ & $\begin{array}{l}6 \cdot 6(2 \cdot 3) \\
6 \cdot 9(2 \cdot 2) \\
5 \cdot 1(2 \cdot 0)\end{array}$ & $\begin{array}{l}4 \cdot 4(1 \cdot 4) \\
4 \cdot 5(1 \cdot 4) \\
4 \cdot 2(1 \cdot 0)\end{array}$ & $\begin{array}{l}11 \cdot 6(2 \cdot 6) \\
11 \cdot 7(2 \cdot 6) \\
10 \cdot 6(2 \cdot 6)\end{array}$ & $\begin{array}{l}0.8(1 \cdot 1) \\
0.8(1 \cdot 1) \\
0.5(0 \cdot 7)\end{array}$ \\
\hline $\begin{array}{l}\text { Symptomatic PE } \\
\text { Frontal } \\
\text { Temporal } \\
\text { Parietal } \\
\text { Occipital }\end{array}$ & $\begin{array}{l}6 \cdot 1(3 \cdot 3) \\
5 \cdot 7(3 \cdot 1) \\
5 \cdot 9(3 \cdot 4) \\
7 \cdot 8(2 \cdot 3) \\
7 \cdot 1(3 \cdot 8)\end{array}$ & $\begin{array}{l}5 \cdot 6(3 \cdot 3) \\
5 \cdot 5(4 \cdot 1) \\
5 \cdot 8(3 \cdot 1) \\
5 \cdot 1(2 \cdot 1) \\
5 \cdot 2(1 \cdot 6)\end{array}$ & $\begin{array}{l}12 \cdot 0(3 \cdot 8) \\
11 \cdot 6(4 \cdot 2) \\
12 \cdot 0(4 \cdot 1) \\
13 \cdot 2(2 \cdot 6) \\
12 \cdot 4(3 \cdot 0)\end{array}$ & $\begin{array}{l}2 \cdot 0(3 \cdot 3) \\
2 \cdot 2(1 \cdot 4) \\
2 \cdot 1(2 \cdot 9) \\
1 \cdot 3(1 \cdot 0) \\
1 \cdot 4(1 \cdot 7)\end{array}$ \\
\hline Cryptogenic PE & $6 \cdot 0(2 \cdot 7)$ & $4 \cdot 1(1 \cdot 7)$ & $10 \cdot 3(2 \cdot 9)$ & $0 \cdot 6(1 \cdot 3)$ \\
\hline $\begin{array}{l}\text { Idiopathic GE } \\
\text { Childhood absence } \\
\text { Juvenile absence } \\
\text { JME } \\
\text { GM (awakening) } \\
\text { Other GM }\end{array}$ & $\begin{array}{r}7 \cdot 1(4 \cdot 0) \\
6 \cdot 4(2 \cdot 1) \\
11 \cdot 8(0 \cdot 9) \\
14 \cdot 6(1 \cdot 8) \\
12 \cdot 3(2 \cdot 3) \\
4 \cdot 7(2 \cdot 4)\end{array}$ & $\begin{array}{l}4 \cdot 1(1 \cdot 7) \\
3 \cdot 8(0 \cdot 7) \\
3 \cdot 7(1 \cdot 7) \\
3 \cdot 4(0 \cdot 1) \\
3 \cdot 5(1 \cdot 3) \\
4 \cdot 7(1 \cdot 8)\end{array}$ & $\begin{array}{r}11 \cdot 9(4 \cdot 1) \\
11 \cdot 0(2 \cdot 1) \\
16 \cdot 0(2 \cdot 3) \\
18 \cdot 2(1 \cdot 8) \\
17 \cdot 0(2 \cdot 2) \\
9.9(3 \cdot 0)\end{array}$ & $\begin{array}{l}0.4(0.9) \\
0.2(0.6) \\
0.6(1 \cdot 2) \\
0.1(0 \cdot 1) \\
0.4(0.8) \\
0.5(1 \cdot 1)\end{array}$ \\
\hline Symptomatic GE & $1.4(1.5)$ & $6 \cdot 0(3 \cdot 4)$ & $7 \cdot 6(3 \cdot 7)$ & $1 \cdot 5(2 \cdot 3)$ \\
\hline $\begin{array}{l}\text { Infantile convulsion } \\
\text { Unclassified }\end{array}$ & $\begin{array}{l}1 \cdot 2(0 \cdot 8) \\
0.6(1 \cdot 1)\end{array}$ & $\begin{array}{l}2 \cdot 6(1 \cdot 3) \\
6 \cdot 4(2 \cdot 5)\end{array}$ & $\begin{array}{r}4 \cdot 0(1 \cdot 6) \\
11 \cdot 8(3 \cdot 5)\end{array}$ & $\begin{array}{l}0 \cdot 2(0 \cdot 7) \\
4 \cdot 3(0 \cdot 6)\end{array}$ \\
\hline
\end{tabular}

Numbers in parentheses are SD; Seizure $=$ duration from the start of antiepileptic drug treatment to seizure cessation. Abbreviations as in table 1.

League Against Epilepsy 1989 $\left.{ }^{14}\right), 72$ patients were diagnosed as having idiopathic partial epilepsies (IPE), 60 as having symptomatic partial epilepsies (SPE), 58 as having cryptogenic partial epilepsies (CPE), 67 as having idiopathic generalised epilepsies (IGE), nine as having cryptogenic or symptomatic generalised epilepsies (SGE), 35 as having benign infantile convulsion (BIC; Fukuyama,
Watanabe ${ }^{1516}$ ), and three were unclassified. The incidence of antiepileptic drug withdrawal differed significantly between epileptic syndromes; it was high in IPE and CPE $(72 \cdot 7 \%$ and $47 \cdot 5 \%$ in all patients, $96 \cdot 8 \%$ and $92.8 \%$ in the patients followed up for more than five years, respectively), IGE ( $52.8 \%$, $83.3 \%)$, and BIC $(52.5 \%, 96.8 \%)$, and low in SPE $(23.4 \%, 52.8 \%)$ and SGE $(23.1 \%$, $21 \cdot 6 \%$ ).

There were some differences between the patients in whom antiepileptic drug treatment could and could not be discontinued. In addition to the differences between epileptic syndromes, those with combined psychomotor delay and epileptic status, and the response to the initial treatment in the first year were also striking (table 2).

\section{FACTORS RELATED TO AGE}

Table 3 shows the mean age at the onset of epilepsy for each syndrome. The duration for the cessation of seizures was shorter in the patients with IPE, CPE, IGE, and BIC than in SPE and SGE. The mean age at withdrawal was nearly the same in IPE, SPE, $\mathrm{CPE}$, and IGE, but much younger in BIC. Thus there was concentration in early adolescence and preschool or early school age. The mean duration of antiepileptic drug treatment was also significantly shorter in the patients with IPE, CPE, and IGE than in those with SPE and SGE.

\section{RELAPSES OF SEIZURES AND EPILEPTIC}

SYNDROMES (table 1)

Forty one patients (13.5\%) experienced a relapse after antiepileptic drug withdrawal. The relapse rate also differed between epileptic groups, being significantly higher in SGE $(33.3 \%)$, and SPE $(20.0 \%)$, but lower in BIC $(5 \cdot 7 \%)$, IPE $(8 \cdot 3 \%)$, and CPE $(8.6 \%)$. In the IGE group, the relapse rate differed with the epileptic syndrome; $6.3 \%$ in childhood absence epilepsy (CAE), $25 \%$ in juvenile absence epilepsy (JAE), $100 \%$ in juvenile myoclonic epilepsy (JME), $27 \cdot 3 \%$ in grand-
Figure 1 Relapse age and interval from antiepileptic drug withdrawal to occurrence of a relapse. IPE = idiopathic partial epilepsies; $S P E=$ symptomatic partial epilepsies; $C P E=$ cryptogenic partial epilepsies; $I G E=$ idiopathic generalised epilepsies, others $=$ other miscellaneous epilepsies.

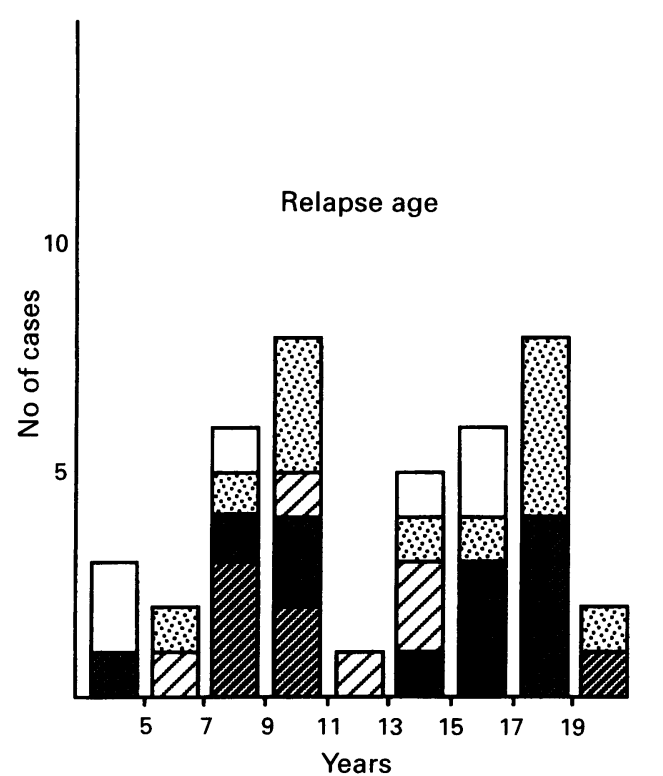

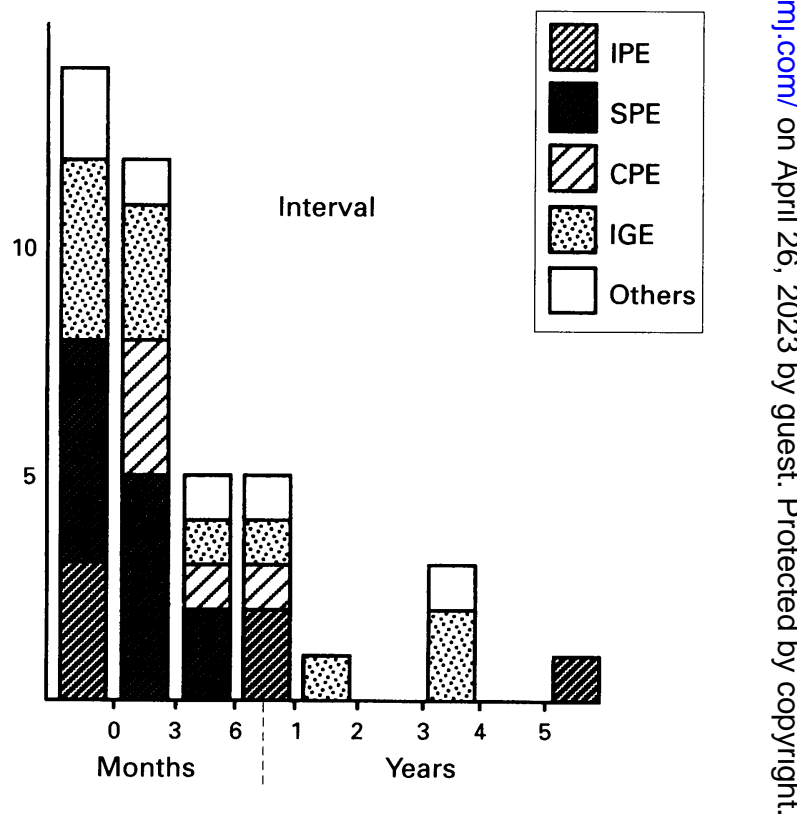


mal (GM) on awakening epilepsy, and $14 \cdot 7 \%$ in other GM epilepsies. Relapses more often occurred in the epilepsies with infantile onset and in those with adolescent or later onset, and were rarer in the epilepsies with school age onset.

\section{AGE AT RELAPSE (fig 1)}

The age of relapse to seizures generally showed two peaks, with age ranges of 7 to 11 and 17 to 19 years. The early peak mainly comprised the relapses in the patients with benign childhood epilepsy with centrotemporal spikes (BECT) and other GM epilepsies, and the late peak those in the patients with each type of SPE and JME, and GM on awakening. In $37(90.2 \%)$ of the 41 relapsers, the relapses occurred during the withdrawal phase or soon afterwards (< one year). The remaining four patients experienced relapses over the three years after the antiepileptic drug withdrawal (in early adulthood), and their seizures were diagnosed as the GM type, differing from the original ones.

The relation between the withdrawal age and the occurrence of relapses was evaluated for each epileptic syndrome (fig 2). The age at withdrawal showed a distinct sharp peak in the patients with idiopathic epilepsies, such as BECT, childhood and juvenile absence epilepsies, other GM epilepsies, and BIC, but patients with symptomatic epilepsies tended to show a wide peak. In BECT, the age at withdrawal was significantly lower in the patients with relapses (9.6 (SD 2.3) years) compared with those without relapses (12.9 (SD 2.4) years). By contrast, in SPE, relapses were often found in patients who had undergone antiepileptic drug withdrawal after adolescence. No obvious tendency was seen in CPE, IGE, or SGE.

\section{FINDINGS ON EEG AND THE RELAPSE TO} SEIZURES

The disappearance of paroxysmal discharges on EEG was attained at the start of antiepileptic drug withdrawal in only $111(42.2 \%)$ of the 263 patients without relapses, and in 17 $(41.5 \%)$ of the 41 with relapses. There was no difference between the two groups for remaining paroxysmal discharges in each epileptic syndrome. The changes and development of the background activity with age differed significantly between the two groups in SPE (fig 3 ). In the patients without relapses, a significant increase in mean frequency, which was associated with a decrease in slow waves and an increase in alpha waves, was recognised during a seizure free period under antiepileptic drug treatment. In the relapsers, the age changes in the background activity were smaller and non-significant compared with those in non-relapsers and normal children.

\section{Discussion}

Modern diagnostic and therapeutic procedures have improved the prognosis of epilepsy, ${ }^{17}$ and many patients (more than $70 \%$ ) may become seizure free. No definite
Figure 2 Withdrawal age and relapse of seizures in each epileptic syndrome. IPE $=$ idiopathic partial epilepsies; $S P E=$ symptomatic partial epilepsies; $C P E=$ cryptogenic partial epilepsy; $I G E-1=$ idiopathic generalised epilepsies with younger onset (childhood absence and other grand mal epilepsies); $B I C=$ benign infantile convulsion, $I G E-2$ = idiopathic generalised epilepsies with later onset (juvenile absence and myoclonic epilepsies, and grand mal on awakening epilepsy): $S G E=$ symptomatic generalised epilepsies; open columns (and dotted columns in BIC) = patients without relapses; shaded columns $=$ those with relapses after antiepileptic drug withdrawal.
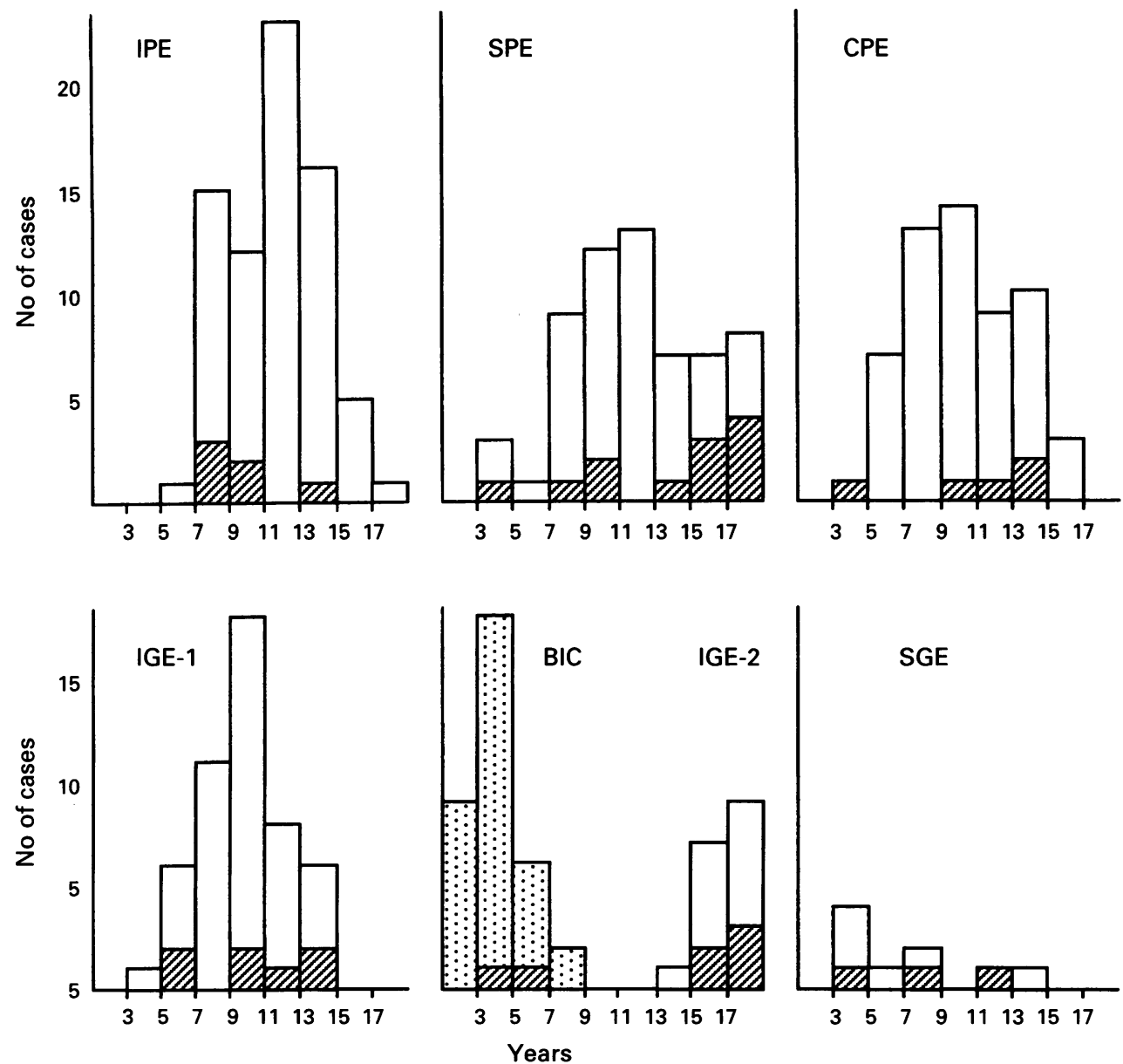
Figure 3 Changes in mean frequency, determined by means of power spectral analysis (O1 delivered), under antiepileptic drug treatment. Left: changes in mean frequency during antiepileptic drug treatment after the last seizure in the patients with relapses after antiepileptic drug treatment. The mean frequencies are almost stationary. Right: changes in patients without relapses. The mean frequencies increase significantly with age, which may indicate normal maturation of the CNS. ${ }_{* \star P}<0.01$
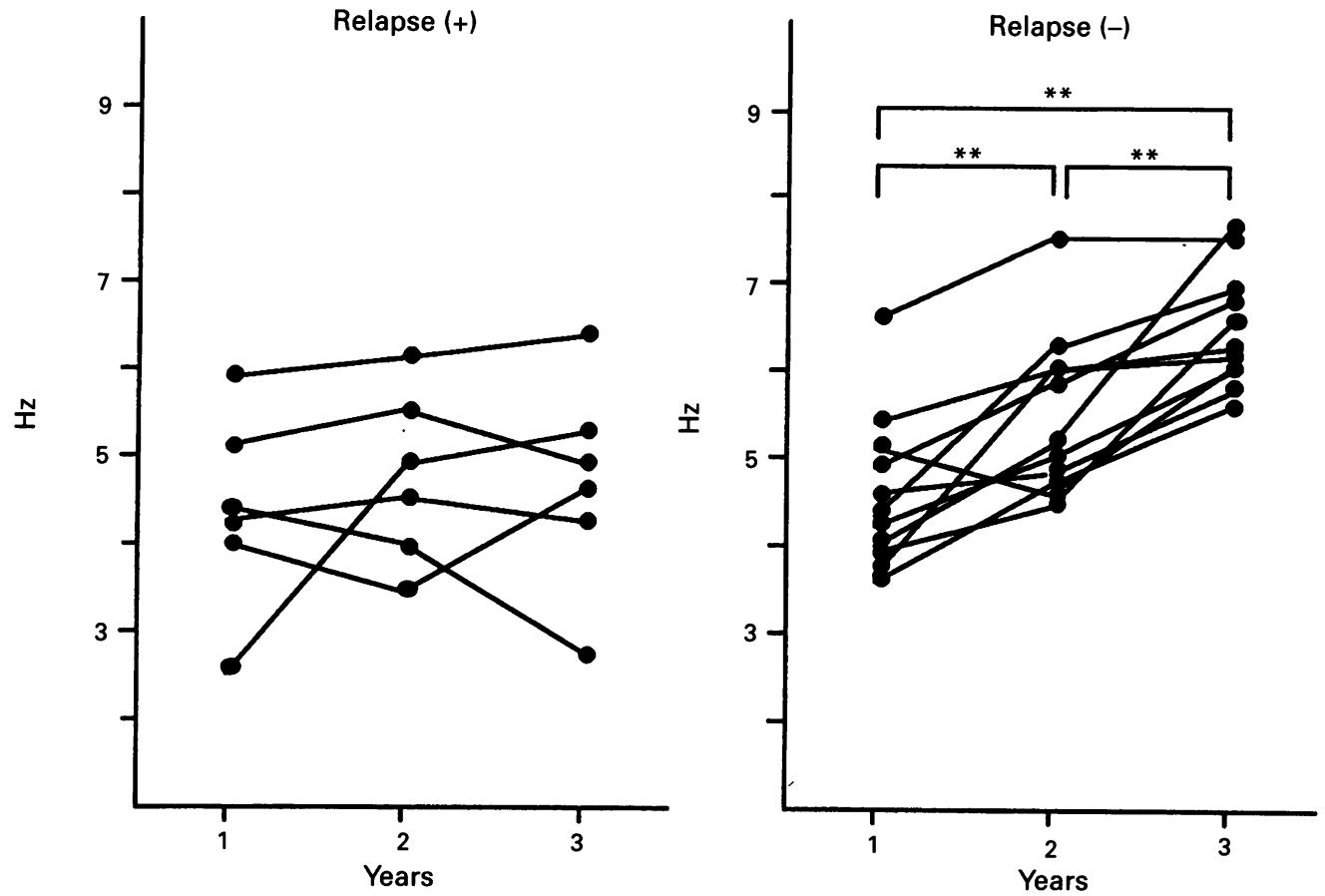

method exists, however, for determining the complete remission of the epilepsies, so the indications of antiepileptic drug withdrawal are still disputed. ${ }^{11}$ Previously, antiepileptic drug withdrawal was done after long term medication by reference to EEG normalisation. But, the EEG findings are not a sufficient guide for antiepileptic drug withdrawal, because remaining paroxysmal discharges do not necessarily mean the occurrence of a relapse after antiepileptic drug withdrawal, and relapses also occur in patients with normal EEGs. Therefore, the decision to withdraw antiepileptic drug in recent studies has mainly been based on the seizure free period (two, three, or five years), ${ }^{6-101213}$ and the duration of medication is becoming shorter.

The relapse rate $(13.5 \%)$ in this study was apparently lower than that in the studies based on a two year seizure free period. But there were significant differences in the rates of withdrawal and relapse between epileptic syndromes; these were favourable in idiopathic and cryptogenic epilepsies, but worse in symptomatic ones. These results suggest that a uniform indication does not always mean a satisfactory outcome in all epileptic syndromes, and additional factors, depending on each epileptic syndrome, should be considered. The duration of medication may be shorter in idiopathic and cryptogenic epilepsies, and longer in symptomatic epilepsies.

Many epilepsies in childhood have an age dependent onset and clinical course, ${ }^{14}$ which may be related to maturation of the CNS. Therefore, these age dependent factors should be considered when making a decision regarding antiepileptic drug withdrawal. The remarkable finding in this study was that there was an age dependent factor concerning both the withdrawal of antiepileptic drug and relapses afterwards. This was judged from the following: (1) the age on antiepileptic drug withdrawal was almost unique to each epileptic syndrome, being more frequent at adolescence and preschool or early school age, and (2) the age of occurrence of relapses showed two peaks, at preadolescence and early adulthood, and also tended to be related to the epileptic syndrome. Furthermore, most of the relapses in BECT were in patients who had undergone antiepileptic drug withdrawal at earlier ages, when the activity of BECT may still be vigorous. ${ }^{18}$ By contrast, in SPE, the relapses were more often seen in patients who had undergone antiepileptic drug withdrawal after adolescence. Their seizures tended to be long term, and ultimately withdrawal was possible after adolescence. This suggests that the age related factor for antiepileptic drug withdrawal and relapse is different in each epileptic syndrome. The characteristic course with age in each epileptic syndrome should be added to the indications for antiepileptic drug withdrawal.

Remaining paroxysmal discharges on EEG after antiepileptic drug withdrawal did not necessarily mean the occurrence of a relapse after treatment, and thus should not affect antiepileptic drug withdrawal. On the other hand, in our preliminary power spectral analysis, the changes in and development of background activity with age were significantly different between the patients with and those without relapses. The EEG background activity has been generally considered to indicate CNS maturation. ${ }^{19} 20$ These results also suggest that the CNS maturation determines whether a relapse after the treatment occurs or not. Background activity therefore seems to be one of the important indicators for the withdrawal of antiepileptic drug treatment.

1 Harrison RM, Taylor DC. Childhood seizures: a 25-year follow-up. Social and medical prognosis. Lancet 1976;i:948-51. 
2 Annegers JF, Hauser WA, Elveback LR. Remission of seizures and relapse in patients with epilepsy. Epilepsia 1979;20:729-37.

3 Elwes RDC, Johnson AL, Schovon SD, Reynolds EH. The prognosis for seizure control in newly-diagnosed epilepsy. N Engl f Med 1984;311:944-7.

4 Broson LO, Wranne L. Long-term prognosis of childhood epilepsy: Survival and seizure prognosis. Epilepsia 1987; 28:324-30.

5 Reynold EH. Early treatment and prognosis of epilepsy. Epilepsia 1987;28:97-106.

6 Emerson R, D'Souza BJ, Vining EP, Holden KR, Mellits ED. Stopping medication in children with epilepsy. $N$ Engl $\mathcal{F}$ Med 1981;304:1125-9.

7 Shinnar S, Vining EP, Mellits ED, et al. Discontinuing antiepileptic medication in children with epilepsy after two years without seizures. $N$ Engl $f$ Med 1985;313: two years

8 Bouma PAD, Peters ACB, Arts RM, Stinen T, Van Rossum J. Discontinuation of antiepileptic therapy: a prospective study in children. $\mathcal{F}$ Neurol Neurosurg Psychiatry 1987;50:1579-83.

9 Arts WFM, Visser LH, Loonen MCB, et al. Follow-up of 146 children with epilepsy after withdrawal of antiepileptic drugs. Epilepsia 1988;29:244-50.

10 Callaghan N, Garrett A, Goggin T. Withdrawal of anticonvulsant drugs in patients free of seizures for two years. N Engl f Med 1988;318:942-6.

11 Chadwick D. Drug withdrawal and epilepsy. When and how? Drugs 1988;35:579-83.

12 Murakami M, Konishi T, Naganuma Y, et al. Clinical and electroencephalographic features in childhood epilepsy with the discontinuation of antiepileptic drugs. fournal of the fapanese Pediatric Society (Tokyo) 1992;96:1684-9. the fapanese
(In Japanese.)

13 Konishi T, Naganuma Y, Hongou K, et al. Discontinuation of antiepileptic drug in childhood epilepsy: Evaluation of the differences between epileptic syndromes. $\mathfrak{F p}_{p} \mathfrak{F}$ Psychiatry Neurol 1994;49:239-44.

14 Commission on Classification and Terminology of the International League Against Epilepsy. Proposal for revised classification of epilepsies and epileptic syndromes. Epilepsia 1989;30:389-99.

15 Fukuyama $Y$. Borderland of childhood epilepsy, with special references to febrile convulsion and so-called infantile convulsion (in Japanese). Clin Psych (Tokyo) 1963;5: 211-23.

16 Watanabe K. Epilepsies in infancy. $f_{p n} \mathcal{f}$ Psychiatry Neurol 1993;47:165-7.

17 Sillanpaa $M$. Proonosis of children with epilepsy. In: Sillanpaa M, Johannessen S, Blennow G, Dam M, eds. Paediatric epilepsy. Petersfield: Wrightson Biomedical Paediatric epilepsy. Peter

18 Lerman P. Benign partial epilepsy with centro-temporal spikes. In: Roger J, Dravet C, Bureau M, Dreifuss FE, Wolf $\mathrm{P}$, eds. Epileptic syndromes in infancy, childhood and adolescence. London: John Libbey, 1985:150-8.

19 Matthis P, Scheffner D, Benninger C, et al. Changes in the background activity of the electroencephalogram according to age. Electroencephalogr Clin Neurophysiol 1980 49:623-35.

20 Benninger C, Matthis P, Scheffner D. EEG development of healthy boys and girls. Results of a longitudinal study. Electroencephalogr Clin Neurophysiol 1984;57:1-12. 